\title{
Geometrical design of micro-textured DLC coatings toward lubricant-free metal forming
}

\author{
Tetsuhide Shimizu, ${ }^{1,}$, Hironori $\mathrm{Kan}^{1}$, Hamza Messaoudi ${ }^{2}$, Frank Vollertsen ${ }^{2,3}$ and Ming Yang ${ }^{1}$ \\ ${ }^{1}$ Department of Intelligent Mechanical Systems, Tokyo Metropolitan University, Tokyo, Japan \\ ${ }^{2}$ BIAS - Bremer Institut für angewandte Strahltechnik, Bremen, Germany \\ ${ }^{3}$ Faculty of Production Engineering-Mechanical Engineering \& Process Engineering, University of Bremen, Bremen, Germany
}

\begin{abstract}
To achieve a stable and high wear resistive functional surface under dry sliding friction, the present study proposes micro-textured diamond like carbon coatings fabricated by ionized physical vapour deposition (I-PVD) using metallic masks. To clarify the optimized geometrical dimensions under dry sliding friction, geometrical conditions of textured array patterns are varied by using metallic masks with different circular hole array patterns fabricated by picosecond pulsed laser processing. The effect of texturing on friction and wear properties is evaluated by ball-on-disk type friction tests for the condition of a constant DLC-coverage per unit area. Thereby, textured DLC pattern with diameters of $50 \mu \mathrm{m}, 100 \mu \mathrm{m}$ and $150 \mu \mathrm{m}$ are applied. Within the first 10,000 laps stable and lower coefficient of friction is obtained with the smallest diameters of $50 \mu \mathrm{m}$. However, at further rotation of more than 40,000 laps, the wear of the smaller diameters becomes more pronounced due to the increase of stress concentration at the edge of the structure. Based on these findings, geometrical design of micro-textured DLC coating is discussed with regard to the suppression of three-body ploughing and the prevention of stress concentration.
\end{abstract}

Keywords: Surface modification, Tribology, Wear

\section{Introduction}

With the growing awareness of environmental issues, the efforts towards a lubricant-free metal forming are intensifying [1]. Since the predominant tribological factors in the case of the dry sliding friction are adhesion and deformation resulting from the direct interaction of surface asperity peaks in contact with each other, the mechanical properties and the geometry of the surface asperities directly affect the friction and wear behaviour [2]. In particular under the plastic deformation of the work materials, as it is the case within a metal forming operation, wear debris of various sizes is generated and the trapped particles at the interface induce a three-body ploughing behaviour, which significantly increases the friction and its large deviations [3].

As a basic concept to suppress the influence of the three-body ploughing caused by generated wear particles, the authors focused on a theoretical model of scale effect of the three body deformation $[4,5]$. It is supposed that wear particles at the edge of an apparent contact area can detach from the surface if these have diameters twice as high than the width of the contact area. In contrast, particles at the centre of the contact region are likely to be trapped and plough the contact surface. Thus, a down scaling of the apparent contact area can help in reducing the three-body ploughing effect. For this purpose, functionalized surfaces are required.
To realize stable dry friction conditions, the authors proposed an application of surface texturing with micro structured diamond like carbon (DLC) coatings to decrease the apparent contact area during sliding [6]. In previous works, micro-textured array patterns fabricated by using metallic wire meshes have demonstrated the low friction with less deviation under dry friction and either in application to sheet bending process [6,7]. Thereby, it was noticed that it is essential to consider the ejection of wear particles from the contact interface as one key factor in the design of suitable surface texturing due to the crucial effect of wear debris generation and its entrapment at the interface. However, the influence of the texture dimensions under dry sliding friction on the tribological properties has not been discussed in details for the representative contact state in metal forming.

The present study performed a systematic approach to vary the geometrical conditions of textured array patterns of DLC coatings. Therefore, metallic masks consisting of different circular hole arrays were fabricated using picosecond laser processing, as flexible and high precise machining method, which ensures a minimized thermal impact as well as distortion-free material ablation [8]. Based on the comparison of tribological properties between different texture dimensions, geometrical design of micro-textured DLC coatings towards lubricant-free metal forming is discussed. 


\section{Experimental}

\subsection{Picosecond laser fabrication of metallic masks}

To ensure a precise and multi-design DLC-deposition procedure, the manufacture of the metallic masks was provided using ultrashort pulsed laser machining. Therefore, a picosecond laser system (TruMicro 5050 from Trumpf $\mathrm{GmbH}$ ) was used. It operates at a wavelength of $1030 \mathrm{~nm}$ in its fundamental Gaussian mode and delivers an average maximum power of $50 \mathrm{~W}$ at $200 \mathrm{kHz}$. It produces pulse widths of $<10 \mathrm{ps}$ and maximum pulse energy of $250 \mu \mathrm{J}$. The collimated laser beam is first expanded and then coupled into a frequency conversion system (Xiton box from Xiton $\mathrm{GmbH}$ ), which allows the second harmonic generation (wavelength of $515 \mathrm{~nm}$ ) in a separated optical path. Thereby, the maximum average power is about $33 \mathrm{~W}$ and the maximum pulse energy is $150 \mu \mathrm{J}$. Depending on the used wavelength the collimated beam is coupled into one of two programmable galvanometer scanners (HurriScan 14 from ScanLab), which enable process speeds up to $12 \mathrm{~m} / \mathrm{s}$. The orthogonal arrangement of the scanner mirrors directs the beam down towards the workpiece using an F-Theta lens (160 mm focal length). This enables both a large scan fields $(100 \mathrm{~mm} \times 100 \mathrm{~mm})$ and small focused laser spot sizes $(48 \mu \mathrm{m}$ and $24 \mu \mathrm{m}$, for $1030 \mathrm{~nm}$ and $515 \mathrm{~nm}$, respectively) at perpendicular incidence of the laser beam. In addition, the workpiece is mounted on a z-axis to ensure the adjustment of the focal plane.

In this work the manufacture of the metallic masks was applied on $10 \mu \mathrm{m}$ thin stainless steel foils over an area of $8 \mathrm{~mm} \times 8 \mathrm{~mm}$. Thereby, the texturing was based on the drilling of circular micro holes having diameters $D$ between $10 \mu \mathrm{m}$ and $150 \mu \mathrm{m}$. Thereby, it has to be mentioned that the targeted diameters were realized at the laser exit side. Moreover, the interspace distance between the holes was varied between $15 \mu \mathrm{m}$ and $75 \mu \mathrm{m}$ in order to realize different DLC-coverage during the deposition procedure. The different mask configurations realized are illustrated in Fig.1.

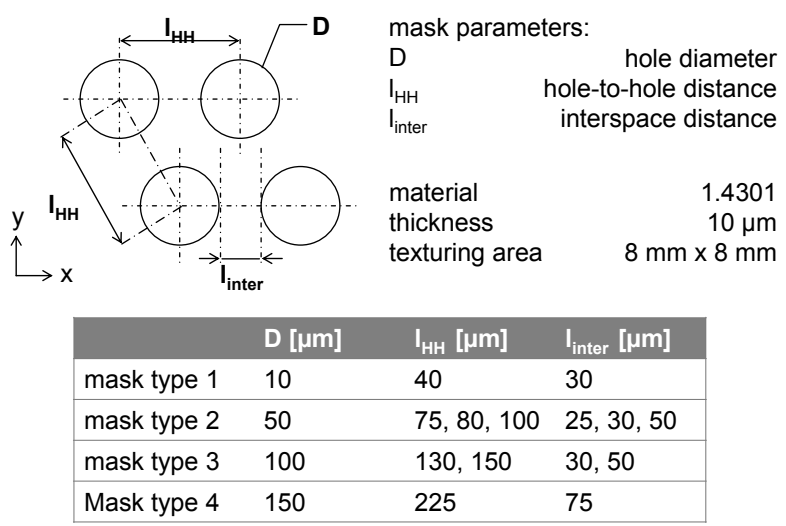

Messaoudi 2018

BIAS ID 180068

Fig. 1. Schematic illustration of the texturing parameters as well the applied mask configurations
A detailed investigation was performed to identify the influence of different process parameters on the resulting hole properties. With respect to the targeted configurations suitable laser parameters (wavelength $\lambda$, pulse energy $E_{p}$, pulse repetition rate $f_{\text {rep }}$, number of pulses $n_{p}$, drilling time per hole $t_{\text {hole }}$ and focal position $\Delta z$ ) were selected, as illustrated in Table 1.

Table 1. Applied laser parameters for the texturing of the different mask configurations

\begin{tabular}{|c|c|c|c|c|c|c|}
\hline $\begin{array}{c}D \\
{[\mu \mathrm{m}]}\end{array}$ & $\begin{array}{c}\lambda \\
{[\mathrm{nm}]}\end{array}$ & $\begin{array}{c}E_{p} \\
{[\mu \mathrm{J}]}\end{array}$ & $\begin{array}{c}f_{\text {rep }} \\
{[\mathrm{kHz}]}\end{array}$ & $\begin{array}{c}n_{p} \\
{[-]}\end{array}$ & $\begin{array}{c}t_{\text {hole }} \\
{[\mathrm{s}]}\end{array}$ & $\begin{array}{c}\Delta z \\
{[\mathrm{~mm}]}\end{array}$ \\
\hline $\mathbf{1 0}$ & 515 & 7.5 & 10 & 800 & 0.08 & 0 \\
\hline $\mathbf{5 0}$ & 1030 & 37.5 & 10 & 600 & 0.06 & 0 \\
\hline $\mathbf{1 0 0}$ & 1030 & 112.5 & 2 & 700 & 0.35 & +2 \\
\hline $\mathbf{1 5 0}$ & 1030 & 137.5 & 2 & 900 & 0.45 & +6 \\
\hline
\end{tabular}

The characterization of the realized metallic masks at the laser exit side was performed using optical microscopy records, from which the hole diameters $D$, the hole-to-hole distance $l_{H H}$ and the interspace distance $l_{\text {inter }}$ were measured.

\section{2 lonized physical vapour deposition of DLC films}

Depositions were performed in an ionized physical vapoured deposition (I-PVD) system (NPS-330S from Nanotec Corp.) with a usable coating volume with a size of $\varphi 150 \mathrm{~mm} \times 150 \mathrm{~mm}$. In this system, the direct current ion source, composed of a tantalum (Ta) filament and anode electrodes, was installed to ionize the benzene $\left(\mathrm{C}_{6} \mathrm{H}_{6}\right)$ gas. Bulk specimens of sintered tungsten carbidecobalt (WC-Co) hard alloy, JIS: V20, with a size of $14 \mathrm{~mm} \times 14 \mathrm{~mm}$ and a thickness of $5 \mathrm{~mm}$ were used as the substrate material. Prior to the deposition, the WCCo substrates were mirror polished, cleaned sequentially in acetone and ethanol, and mounted on a table with fixing jigs. Starting with a base pressure of $<5 \times 10^{-3} \mathrm{~Pa}$, argon (Ar) gas of $10 \mathrm{sccm}$ was introduced to initiate an Ar plasma and remove the adsorption layers on the substrates by plasma etching process.

Table 2. Conditions of DLC deposition by I-PVD process.

\begin{tabular}{|l|l|}
\hline Pre-treatment of substrate & $\begin{array}{l}\mathrm{Ar}^{+} \text {bombard } \\
\mathrm{DC}-1 \mathrm{kV} \text { for 30min }\end{array}$ \\
\hline Gas species & $\mathrm{C}_{6} \mathrm{H}_{6}$ \\
\hline Gas flow rate $\quad[\mathrm{sccm}]$ & 0.75 \\
\hline Gas pressure $\quad[\mathrm{Pa}]$ & $2.5 \times 10^{-2}$ \\
\hline Bias voltage $\quad[\mathrm{kV}]$ & -1 \\
\hline Filament current $\quad[\mathrm{A}]$ & 30 \\
\hline Temperature $\quad\left[{ }^{\circ} \mathrm{C}\right]$ & 250 \\
\hline Deposition time $\quad[\mathrm{h}]$ & 2 \\
\hline
\end{tabular}

The pre-treatment was performed using a DC-voltage of $-1 \mathrm{kV}$ for $30 \mathrm{~min}$. Subsequently, the DLC deposition was carried out in a $\mathrm{C}_{6} \mathrm{H}_{6}$ atmosphere at $250{ }^{\circ} \mathrm{C}$. The 
$\mathrm{C}_{6} \mathrm{H}_{6}$ flow was set to $0.75 \mathrm{sccm}$ to maintain a total pressure of $2.5 \times 10^{-2} \mathrm{~Pa}$. Throughout the deposition, the substrate bias voltage was maintained at $-1 \mathrm{kV}$. The conditions of the complete process are summarized in Table 2.

\subsection{Tribological evaluations}

To characterize the basic tribological properties of the fabricated non-textured and micro-textured DLC films under dry sliding conditions, ball-on-disk type tribology tests were carried out with a commercial tribometer (TRIBOMETER, CSM Instruments). A constant normal force of $5 \mathrm{~N}$, which corresponds to an initial Hertzian mean contact pressure of about $1.2 \mathrm{GPa}$ and elastic contact diameter of approx. $110 \mu \mathrm{m}$, was applied for the all testing samples. This contact pressure is equivalent to that generally assumed in the severe contact state in metal forming, such as ironing or forging process. As a counterpart, an alumina $\left(\mathrm{Al}_{2} \mathrm{O}_{3}\right)$ ball with a dimeter of $6 \mathrm{~mm}$ was used. The tests were performed under unlubricated condition and with a linear speed of $42 \mathrm{~mm} / \mathrm{s}$ at room temperature in ambient air. Wear tracks of the substrates and sliding balls were analyzed by optical microscopy and scanning electron microscopy (SEM). In addition, the chemical composition at the contact surface was also analyzed by energy dispersive $\mathrm{X}$-ray spectroscopy (EDS).

\section{Results and discussion}

\subsection{Laser manufactured metallic masks}

The first step in this work was the manufacture of the metallic masks following the design required for the subsequent DLC-deposition. Figure 2 shows selected microscopic images of different mask configurations. The images show that the laser machining enables a high reproducibility as well as high dimensional accuracy.
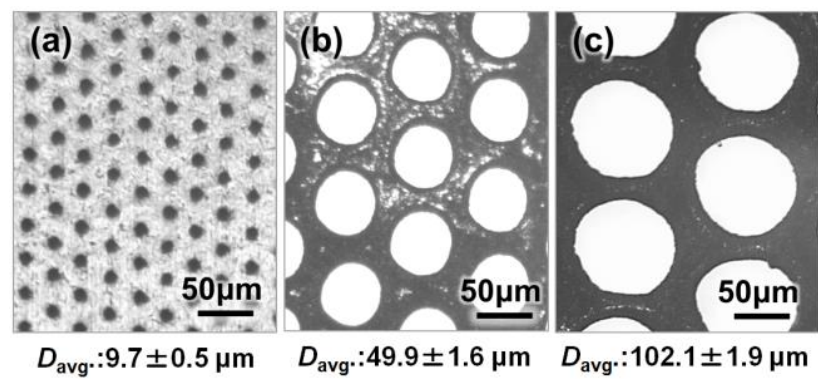

Fig. 2. Optical microscopic images of picosecond laser processed metallic masks with diameters $D$ of $10 \mu \mathrm{m}$ (a), $50 \mu \mathrm{m}$ (b) and $100 \mu \mathrm{m}$ (c) and a constant interspace distance $l_{\text {inter }}$ of $30 \mu \mathrm{m} .{ }^{*} D_{\text {avg }}$ : Averaged diameter.

\subsection{Fabrication of micro-textured DLC films}

By using the micro-perforated metallic masks, a microtexturing of thin DLC films was realized during the deposition process. Figure 3 shows examples of microtextured DLC films and their related surface profile obtained using a 3D surface profiler. The circular island structure patterns with diameters of approx.10 $\mu \mathrm{m}$, $50 \mu \mathrm{m}$ and $100 \mu \mathrm{m}$ and a constant interspace distance of $30 \mu \mathrm{m}$ are characterized by high dimension accuracy as well as sharp edges. Thereby, the thickness of the DLC coating was $\approx 300 \mathrm{~nm}$ for all geometrical conditions.
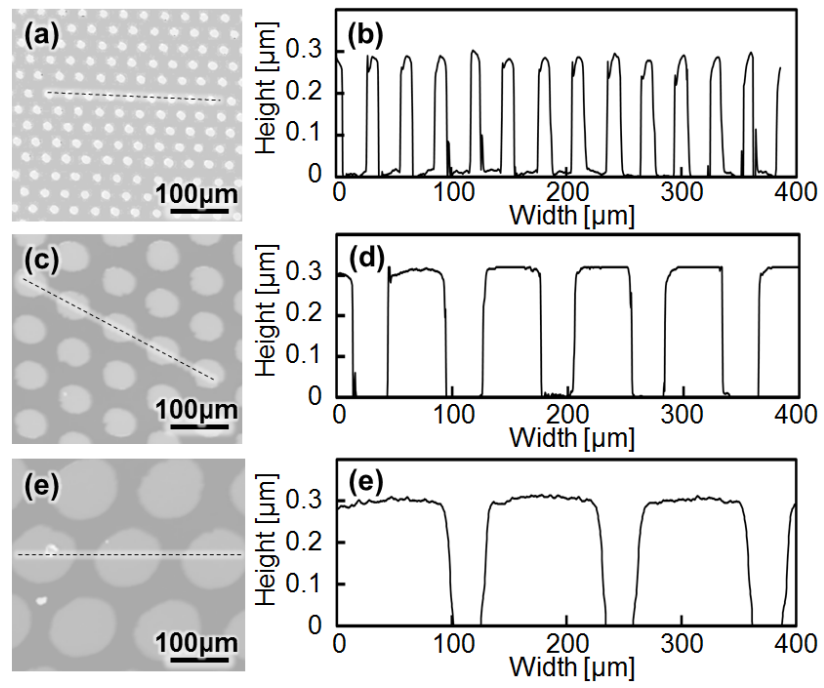

Fig. 3. Microscopic images of micro-textured DLC coatings and their surface profile with a texture diameter of $10 \mu \mathrm{m}$ (a),(b), $50 \mu \mathrm{m}$ (c),(d) and $100 \mu \mathrm{m}$ (e),(f).

\subsection{Comparison of tribological properties between different textured dimensions}

Ball-on-disk tests were carried out to characterize the tribological properties in dependence of the applied texturing. In order to evaluate the effect of texture diameter under the same apparent contact pressure, following three geometrical conditions were chosen to keep a constant ratio of the DLC-coverage in unit area $(40 \%) ; D=50 \mu \mathrm{m}$ with $l_{\text {inter }}=25 \mu \mathrm{m}, D=100 \mu \mathrm{m}$ with $l_{\text {inter }}=50 \mu \mathrm{m}$ and $D=150 \mu \mathrm{m}$ with $l_{\text {inter }}=75 \mu \mathrm{m}$.

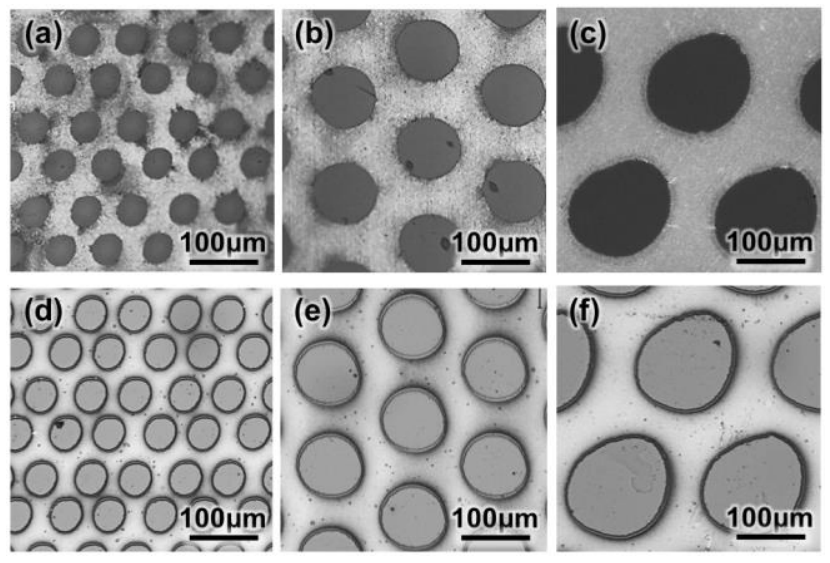

Fig. 4. Optical microscopic images of the laser processed metallic masks with different diameter $D$ of $50 \mu \mathrm{m}$ (a), $100 \mu \mathrm{m}$ (b) and $150 \mu \mathrm{m}$ (c) with a constant DLC coverage and that of the corresponding micro-textured DLC (d), (e), (f). 
Fig. 4 shows the optical images of the laser machined metallic masks and the corresponding microtextured DLC. Thereby, it is visible that the precise micro-textured array patterns were successfully obtained as they were originally designed for metallic masks.

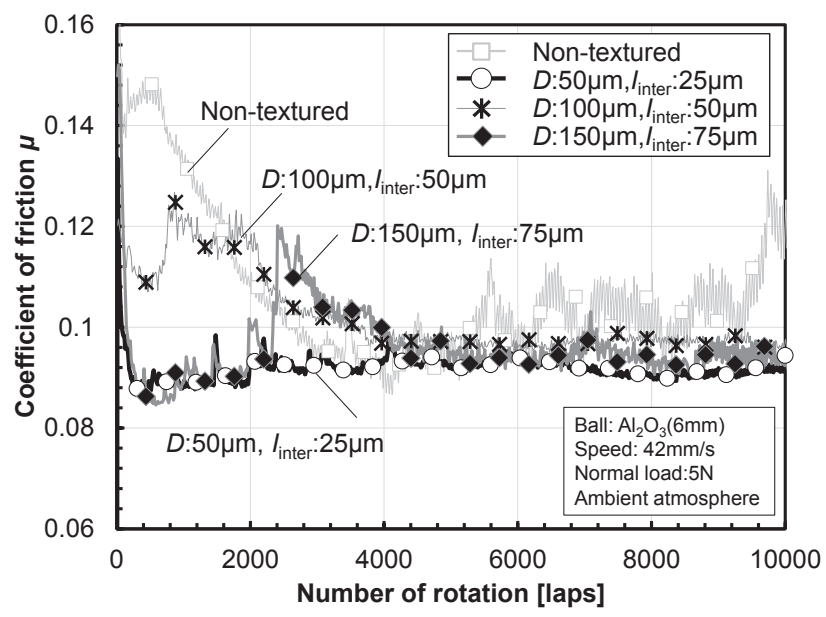

Fig. 5. Evolution of COF during initial 10,000 laps of ball-ondisk friction test of non-textured and micro-textured DLC films with different texture dimensions.

Fig. 5 shows the evolution of the coefficient of friction (COF) during 10,000 laps of rotations in ball-ondisk friction tests for both, non-textured and microtextured DLC films. As expected, a high COF with relatively large deviation is shown for the non-textured films. In contrast, the use of textured DLC shows a significant influence of the texture diameter on the resulting COF in the first 5,000 laps of rotation. However, the variation of $\mathrm{COF}$ reduces and becomes more stable above the second 5,000 laps. In particular, the texture with the smallest diameter of $50 \mu \mathrm{m}$ shows a relatively low COF value of $\mu=0.09$ with almost no deviations from the initial rotation. This stability in smaller diameter texture is assumed to be due to the suppression of ploughing by the wear debris at contact interface [3]. Taking into account the scale effect of the three-body deformation, the real area of contact of threebody ploughing is approximately $1 / 6$ at the original scale dimensions by scaling down the apparent contact area to the half [9]. Thus, the entrapment probability of wear debris decreases and thereby contributes to the stable and reduced friction under dry sliding conditions.

Above 1000 laps of rotation in the ball-on-disk friction tests, however, the micro-textured DLC with smallest texture diameter of $50 \mu \mathrm{m}$ shows a limited durability compared to that with the largest texture diameter of $150 \mu \mathrm{m}$, see Fig. 6 . After approx. 20,000 laps of rotation, the COF of the texture diameter of $100 \mu \mathrm{m}$ increases significantly, while that of $50 \mu \mathrm{m}$ increases after 40,000 laps. In comparison, the texture patterns with diameter of $150 \mu \mathrm{m}$ reveal more than twice longer durability up to $>80,000$ laps. Thereby, the COF level is maintained constant around $\mu=0.08$.

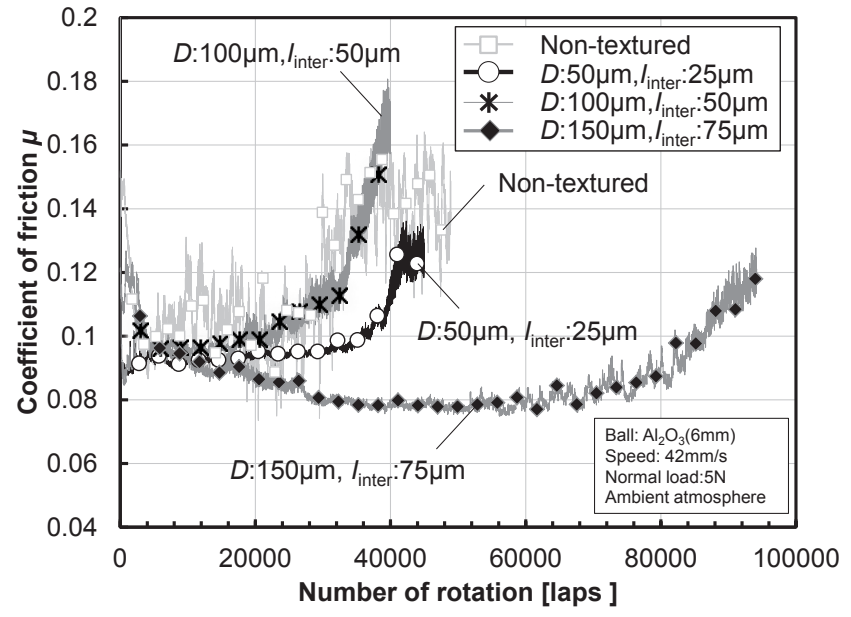

Fig. 6. Evolution of COF during ball-on-disk friction test of non-textured and micro-textured DLC films with different texture dimensions.

As can be seen in Fig. 7(a) to (c), the DLC coating on the patterns with the largest diameters $(D=150 \mu \mathrm{m})$ is remained after the 90,000 laps of rotation, while on the pattern with smaller diameters of $50 \mu \mathrm{m}$ and $100 \mu \mathrm{m}$ the DLC layer is almost worn after 40,000 laps of rotation. In fact, the wear debris including large amount of carbon contents was accumulated beside the sliding tracks for the textured diameter of $50 \mu \mathrm{m}$ and $100 \mu \mathrm{m}$, which shows the wear of the textured DLC structure even under the same coverage of DLC films at unit area. According to the classical empirical equation of wear volume proposed by Archard [10], those higher wear rates in smaller textured structure seem to be attributed to the higher local surface pressure for the smaller diameters during the sliding of the spherical surface of the ball. In particular, the stress concentration at the edge of the texture during the sliding promotes the wear of the texture structure. As seen in the Fig. 7(b), the right edge of the texture structure is preferentially worn, where the stress concentration of the ball is more pronounced due to the sliding direction.
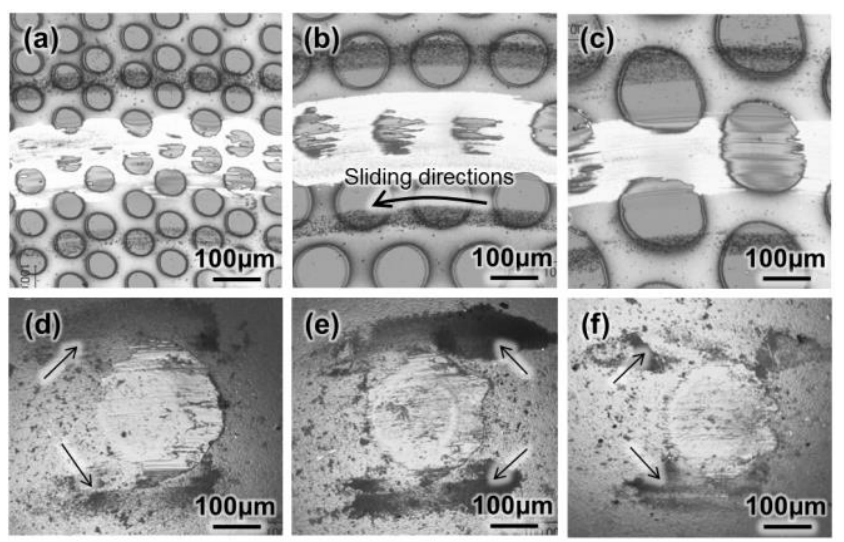

Fig. 7. Optical surface images of wear tracks of micro-textured DLC films with different texture diameters of $50 \mu \mathrm{m}$ (a), $100 \mu \mathrm{m}$ (b), $150 \mu \mathrm{m}$ (c) as well as the corresponding counterparts of alumina balls (d), (e), (f), respectively, after the ball-on-disk friction tests. 
In addition, the comparison between Fig. 7(d) and (e) indicates that the accumulation of carbon wear debris beside the worn spots at the alumina balls is less for textured diameter of $50 \mu \mathrm{m}$ than that of $100 \mu \mathrm{m}$. Thus, it is suggested that the generated wear debris did not accumulate owing to the effective ejection of wear debris by the scale effects of three-body ploughing and it might contribute to the slightly higher durability for the texture diameter of $50 \mu \mathrm{m}$ than $100 \mu \mathrm{m}$. In view of this accumulation of the carbon particles, it is clearly seen the less amount of accumulation for the texture diameter of $150 \mu \mathrm{m}$, which has the longest durability, as shown in Fig, 7 (f).

For the design of micro-texture that fulfil the requirements of a durable dry sliding, the balance between the efficient ejection of wear debris from contact interface, which can be realized by scaling down of the apparent contact area, and the suppression of the stress concentration by decreasing the interspace to distribute the stress with surrounding textures represent the key parameters to determine the geometrical dimensions. As an approach to ensure the suppression of stress concentration at the structure edges, the structural analysis can be used to modify both, the structure geometry and dimensions.

\section{Conclusions}

Through the tribological evaluation of ball-on-disk type friction tests under constant DLC-coverage and varied structure diameter, following conclusions can be drawn:

- Within the 10,000 laps of rotation, smaller texture diameter $(D=50 \mu \mathrm{m})$, stable and relatively low COF of $\mu=0.09$ was measured, which is probably the results of an effective ejection of wear debris from the contact interface.

- Regarding the wear resistance, larger DLC structures $(D=150 \mu \mathrm{m})$ showed more than twice longer durability than that of smaller diameter, which was characterized by low COF of $\mu=0.08$. The lower wear resistance of the textures with smaller diameters is attributed to the higher stress concentration at the edge of the structure, which can be modified by structural design of the microtexture patterns.

In summary, stable and reduced friction under dry sliding condition can be achieved by a miniaturization of apparent contact area of textured surface, while durable wear resistivity by taking into account the ejection of wear debris from contact interface and the stress concentration. Future works will focus on quantitative structural analysis in order to design appropriate geometrical structures.

The authors gratefully thank the financial support from Tokyo Metropolitan University in the framework of the Co-Tutorial Program in 2016 as well as from the minister for science, health and consumer protection of the free hanseatic city Bremen.

\section{References}

1. N. Bay, A. Azushima, P. Groche, I. Ishibashi, M. Merklein, M. Morishita, T. Nakamura, S. Schmid \& M. Yoshida CIRP Ann. 59, 760-780 (2010)

2. B. Bhushan, Introduction to Tribology 2nd Edition (Wiley, New York), (2013)

3. N.P. Suh \& H.C. Sin, Wear 69, 91-114 (1981)

4. B. Bhushan \& M. Nosonovsky, Acta Mater. 52, 2461-2474 (2004)

5. M. Nosonovsky, B. Bhushan, Scale effect in dry friction during multiple-asperity contact, ASME J. Tribol. 127, 37-46 (2005)

6. T.Shimizu, T. Kakegawa \& M. Yang, Procedia Eng. 81, 1884-1889(2014)

7. T. Kakegawa, T. Shimizu \& M. Yang, J. Jpn Soc. Technol. Plast. 56-657, 891-896 (2015) (in Japanese)

8. J.Meijer, K. Du, A.Gillner, D. Hoffmann, V.S. Kovalenko, T.Masuzawa, A.Ostendorf, R.Poprawe, W.Schulz, CIRP Annals 51(2), 531-550 (2002)

9. T. Shimizu, M. Yang \& K. Manabe, Wear 330-331, 49-58 (2015)

10. E. Rabinowicz: Friction and Wear of Materials, (Wiley, New York), (1995) 